\title{
ESTUDO DA PRODUÇÃO DE BIOSSURFACTANTE EM CALDO DE FERMENTAÇÃO
}

\author{
Silvia Messias Bueno, Adriana Navarro da Silva* e Crispin Humberto Garcia-Cruz \\ Instituto de Biociências, Letras e Ciências Exatas, Universidade Estadual Paulista, R. Cristóvão Colombo, 2265, 15054-000 São \\ José do Rio Preto - SP, Brasil \\ Recebido em 17/6/09; aceito em 27/2/10; publicado na web em 10/6/10
}

\begin{abstract}
STUDY ON THE PRODUCTION OF BIOSURFACTANT FERMENTATION BROTH. A bacterium isolated from soil contaminated by hydrocarbon was studied and, by biochemical tests and analysis of PCR, the presence of Bacillus pumilus was identified. The production of biosurfactant was optimized, test of oil degradation and antimicrobial activity determination. The results showed that pH 5.0 and 7.0, $72 \mathrm{~h}$ of fermentation, sucrose and sugar cane juice (2\%) had best yields. The bacterium is able to degrade crude oil and displays bacteriostatic and fungistatic activity. From the analysis of proximate composition of biosurfactant found the presence of biopolymer formed by a lipopolysaccharide-protein complex.
\end{abstract}

Keywords: biosurfactant; microorganism; fermentation.

\section{INTRODUÇÃO}

Os surfactantes são agentes ativos de superfície que reduzem a energia livre do sistema por substituir a maior parte das moléculas de alta energia na interface diminuindo, assim, a tensão superficial e interfacial dos líquidos; estes são constituídos por uma porção hidrofóbica e um grupo hidrofílico, sendo conhecidos também por substâncias anfifílicas. ${ }^{1}$

A maioria dos surfactantes utilizados comercialmente é sintetizada a partir de derivados do petróleo, entretanto, o aumento da preocupação ambiental combinado com as novas legislações de controle do meio ambiente levou à procura por surfactantes biológicos em decorrência de serem biodegradáveis diminuindo, assim, o impacto ambiental. Os biossurfactantes possuem características benévolas ao meio ambiente e ocorrem naturalmente no solo, além disso, possuem aplicações potenciais em diferentes setores industriais como formulações farmacêuticas e cosméticas, petroquímica, médica, produtos alimentícios e nas áreas de proteção ao meio ambiente. ${ }^{2-6}$ Há uma ampla possibilidade de mercado para os biossurfactantes como, por exemplo, a indústria de petróleo para biorremediação/dispersão, tanto no solo quanto no mar, durante os derramamentos de óleo; remoção/ mobilização de óleos incrustados em tanques de estocagem, rochas e areia do mar, aumentando a sua recuperação. ${ }^{2}$

Os micro-organismos sintetizam compostos com propriedades surfactantes como subprodutos metabólicos sendo, neste caso, denominados biossurfactantes e podem ser isolados de amostras de solos contaminados e não contaminados por hidrocarbonetos. ${ }^{7}$ As bactérias, juntamente com as arqueobactérias, são os maiores responsáveis pela produção destes compostos tensoativos; bactérias das famílias Pseudomonacea e Bacillacea são capazes de produzirem biossurfactantes eficientes na remoção de petróleo e seus derivados poluentes de água. ${ }^{8}$ Os biossurfactantes produzidos por micro-organismos podem ser obtidos utilizando-se procedimentos relativamente simples e substratos baratos, através de processos de fermentação. Açúcares e óleos são fontes de carbono adequadas para a obtenção de tensoativos ecologicamente seguros. ${ }^{9}$

\section{PARTE EXPERIMENTAL}

\section{Micro-organismos}

Para a produção dos biossurfactantes microbianos foi utilizada a bactéria do gênero Bacillus pumilus isolada de amostra de solo contaminado por hidrocarbonetos, inicialmente denominada de $2 \mathrm{C}$, a qual foi identificada através de testes bioquímicos com auxílio do manual Bergey's ${ }^{10}$ e análise da reação em cadeia da polimerase (PCR) através do gene RNA ribossomal 16S.

\section{Meio de produção de biossurfactante}

O meio base empregado para a fermentação foi composto por $(\mathrm{g} / \mathrm{L})$ : $\mathrm{MgSO}_{4} .7 \mathrm{H}_{2} \mathrm{O}(0,5) ; \mathrm{KCl}(0,1) ; \mathrm{KH}_{2} \mathrm{PO}_{4}(0,5) ; \mathrm{CaCl}_{2}(0,01) ; \mathrm{K}_{2} \mathrm{HPO}_{4}$ $(1,0) ; \mathrm{NaNO}_{3}(7,0) ; \mathrm{FeSO}_{4} .7 \mathrm{H}_{2} \mathrm{O}(0,01)$; extrato de levedura $(0,1)$ e óleo diesel $1,0 \%(\mathrm{v} / \mathrm{v})$ acrescido da fonte de carbono selecionada. ${ }^{11} \mathrm{~A}$ bactéria Bacillus pumilus foi inoculada em tubos de ensaio contendo $5 \mathrm{~mL}$ de caldo nutriente e incubada por $24 \mathrm{~h}$ a $30^{\circ} \mathrm{C}$. Após a incubação, as suspensões de células de cada tubo foram submetidas a leituras de densidade óptica a $650 \mathrm{~nm}$ para padronização celular a 0,05 e foram transferidas para frascos Erlenmeyer de $250 \mathrm{~mL}$ contendo $45 \mathrm{~mL}$ de meio de produção. A seguir foram incubadas a $30^{\circ} \mathrm{C}$ e $200 \mathrm{rpm}$. O caldo de fermentação foi centrifugado a $9000 \mathrm{rpm}$ por $20 \mathrm{~min}$ a $4{ }^{\circ} \mathrm{C}$ para separação das células.

\section{Parâmetros fermentativos testados}

Foram testados diferentes pHs $(5,0 ; 6,0 ; 7,0 ; 8,0)$, tempo de fermentação (48, 72 e 96 h) e diferentes fontes de carbonos como glicose, sacarose, manitol, frutose, glicose + frutose e caldo de cana nas concentrações de 1 a $5 \%$.

\section{Determinação da presença de biossurfactantes}

Os caldos fermentados isentos de células foram submetidos à análise de tensão superficial, índice de emulsificação, atividade emulsificante, concentração micelar crítica (CMC), determinação do crescimento celular, degradação do petróleo, atividade antimicrobiana, purificação do biossurfactante e determinação da composição do biossurfactante. 


\section{Determinação da tensão superficial}

A medida da tensão superficial foi determinada diretamente da superfície do sobrenadante com um tensiômetro de Leconde Du Nouy.

Índice de emulsificação $\left(E_{24}\right)$

Foi determinado pela adição de $2,0 \mathrm{~mL}$ de tolueno em $3,5 \mathrm{~mL}$ do sobrenadante, misturando-se em vortex por 2 min e deixando em repouso por $24 \mathrm{~h}$. O índice foi calculado como porcentagem da altura da camada emulsificada $(\mathrm{cm})$ dividida pela altura total da coluna do líquido $(\mathrm{cm}){ }^{11}$

\section{Determinação da atividade emulsificante}

A determinação da atividade emulsificante foi testada agitando-se $3,5 \mathrm{~mL}$ da solução do biossurfactante com $2 \mathrm{~mL}$ de tolueno e fazendose a leitura da densidade óptica em espectrofotômetro a $610 \mathrm{~nm}$.

\section{Determinação da concentração micelar crítica (CMC)}

A determinação da CMC foi realizada através de medidas de tensão superficial do sobrenadante (livre de células) diluindo-se sucessivamente (volumes iguais de água) até o valor da tensão se aproximar ao valor da água. O valor de CMC foi dada pelo ponto central da inflexão da curva do gráfico tensão superficial versus porcentagem de sobrenadante contendo o biossurfactante.

\section{Determinação do crescimento celular}

A determinação do crescimento celular foi realizada através do peso seco das células obtidas durante a produção, as quais foram transferidas quantitativamente com água destilada para placas de Petri pré-pesadas e secas em estufa a vácuo a $45^{\circ} \mathrm{C}$ até peso constante.

\section{Degradação do petróleo}

Placas de Petri contendo areia (10 g), inóculo bacteriano e petróleo $(1 \%)$ foram incubadas a $30{ }^{\circ} \mathrm{C}$ por 20 dias. O controle negativo não possuía inoculo; após este período, as placas foram submetidas à análise macroscópica para observação da degradação do petróleo.

\section{Atividade antimicrobiana}

A determinação da atividade antimicrobiana foi determinada com a bactéria Bacillus pumilus (apenas para as placas) e com seu sobrenadante (após fermentação e separação das células) contendo o biossurfactante por dois métodos: em placas de Petri contendo meio
PCA inoculadas com bactérias Gram positivas e Gram negativas e meio PDA incubada com fungo. O tamanho do halo de inibição indicou a atividade antimicrobiana; em tubos de ensaio contendo caldo nutriente inoculadas com bactérias Gram positivas e Gram negativas e fungo. A inibição foi detectada com auxílio de espectrofotômetro a $620 \mathrm{~nm}$.

Todas as análises foram realizadas em triplicata.

\section{Purificação do biossurfactante}

O biossurfactante precipitado do sobrenadante livre de células com etanol (1:2) foi purificado por diálise usando-se uma membrana de diâmetro $2,5 \mathrm{~cm}$ e poro $10 \mathrm{kDa}$ em água destilada. A diálise foi realizada durante $72 \mathrm{~h}$ e a água da diálise trocada 3 vezes ao dia.

\section{Determinação da composição do biossurfactante}

Para a determinação de sua composição o biossurfactante purificado foi analisado por ressonância magnética nuclear (RMN) e foi realizada a análise da presença de proteína pelo método de Kjeldahl, ${ }^{12}$ presença de gordura por Bligh-Dyer, ${ }^{13}$ açúcares redutores e açúcares totais por Somogy-Nelsone Dubois. ${ }^{14-16}$

\section{RESULTADOS E DISCUSSÃO}

\section{Determinação dos parâmetros de produção}

Para a determinação dos parâmetros de produção do biossurfactante foi utilizado o meio sintético acrescido de uma fonte de carbono, o meio foi inoculado com a bactéria Bacillus pumilus isolada de amostra de solo contaminado por hidrocarbonetos, a qual foi previamente identificada através de testes bioquímicos e análise de PCR.

Foram testados os diferentes pHs $(5,6,7$ e 8$)$ e os diferentes tempos de fermentação $(48,72$ e $96 \mathrm{~h})$ para escolha do melhor parâmetro de produção para, em seguida, serem testadas as diferentes fontes de carbono (glicose, sacarose, manitol e caldo de cana, frutose e glicose + frutose) em diferentes concentrações (1, 2, 3, 4 e 5\%).

Foram escolhidos os tempos de fermentação de 48 e $72 \mathrm{~h}$, pois estudos realizados por diferentes autores mostraram que o máximo crescimento das bactérias dos gêneros Bacillus ocorre em $12 \mathrm{~h}$ e permanece constante até $72 \mathrm{~h}$, com posterior declínio, e a produção de biossurfactante ocorre na fase estacionária. ${ }^{17-19}$

Para testar os diferentes $\mathrm{pH}$ e tempos de fermentação em agitador orbital rotatório, foi realizado um acompanhamento utilizando

Tabela 1. Tensão superficial (Din/cm) para determinação do melhor pH e tempo de fermentação para a produção de biossurfactantes

\begin{tabular}{|c|c|c|c|c|c|c|c|c|c|c|c|c|}
\hline \multirow[t]{2}{*}{ Amostras } & \multicolumn{3}{|c|}{$\mathrm{pH}=5,0$} & \multicolumn{3}{|c|}{$\mathrm{pH}=6,0$} & \multicolumn{3}{|c|}{$\mathrm{pH}=7,0$} & \multicolumn{3}{|c|}{$\mathrm{pH}=8,0$} \\
\hline & $48 \mathrm{~h}$ & $72 \mathrm{~h}$ & $96 \mathrm{~h}$ & $48 \mathrm{~h}$ & $72 \mathrm{~h}$ & $96 \mathrm{~h}$ & $48 \mathrm{~h}$ & $72 \mathrm{~h}$ & $96 \mathrm{~h}$ & $48 \mathrm{~h}$ & $72 \mathrm{~h}$ & $96 \mathrm{~h}$ \\
\hline B. pumilus & 57,8 & 56,0 & 56,0 & 60,5 & 57,8 & 58,0 & 57,0 & 54,0 & 55,0 & 60,0 & 57,5 & 58,4 \\
\hline B. subtilis & 56,1 & 53,7 & 53.8 & 59,5 & 55,7 & 56,3 & 55,2 & 54,0 & 56,0 & 60,0 & 58,0 & 58,5 \\
\hline
\end{tabular}

Meio base: $66,1 \mathrm{Din} / \mathrm{cm}, \operatorname{Din} / \mathrm{cm}=\mathrm{mN} / \mathrm{m}$

Tabela 2. Índices de emulsificação (em porcentagem) determinados a diferentes pHs e tempos de fermentação para a produção de biossurfactantes

\begin{tabular}{|c|c|c|c|c|c|c|c|c|c|c|c|c|}
\hline \multirow[t]{2}{*}{ Amostras } & \multicolumn{3}{|c|}{$\mathrm{pH}=5,0$} & \multicolumn{3}{|c|}{$\mathrm{pH}=6,0$} & \multicolumn{3}{|c|}{$\mathrm{pH}=7,0$} & \multicolumn{3}{|c|}{$\mathrm{pH}=8,0$} \\
\hline & $48 \mathrm{~h}$ & $72 \mathrm{~h}$ & $96 \mathrm{~h}$ & $48 \mathrm{~h}$ & $72 \mathrm{~h}$ & $96 \mathrm{~h}$ & $48 \mathrm{~h}$ & $72 \mathrm{~h}$ & $96 \mathrm{~h}$ & $48 \mathrm{~h}$ & $72 \mathrm{~h}$ & $96 \mathrm{~h}$ \\
\hline B. pumilus & 37,7 & 48,8 & 40,0 & 33,3 & 37,7 & 33,3 & 35,5 & 44,4 & 40,0 & 35,5 & 37,7 & 35,5 \\
\hline B. subtilis & 11,1 & 15,5 & 12,2 & 0,0 & 8,8 & 0,0 & 11,1 & 11,1 & 11,1 & 11,1 & 1,11 & 11,1 \\
\hline
\end{tabular}

Tabela 3. Peso celular seco (g) em $50 \mathrm{~mL}$ de meio de fermentação em diferentes pHs e tempos de fermentação

\begin{tabular}{|c|c|c|c|c|c|c|c|c|c|c|c|}
\hline \multirow[t]{2}{*}{ Amostras } & \multicolumn{3}{|c|}{$\mathrm{pH}=5,0$} & \multicolumn{3}{|c|}{$\mathrm{pH}=6,0$} & \multicolumn{2}{|c|}{$\mathrm{pH}=7,0$} & \multicolumn{3}{|c|}{$\mathrm{pH}=8,0$} \\
\hline & $48 \mathrm{~h}$ & $72 \mathrm{~h}$ & $96 \mathrm{~h}$ & $48 \mathrm{~h}$ & $72 \mathrm{~h}$ & $96 \mathrm{~h}$ & $48 \mathrm{~h}$ & $72 \mathrm{~h}$ & $48 \mathrm{~h}$ & $72 \mathrm{~h}$ & $96 \mathrm{~h}$ \\
\hline B. pumilus & 0,116 & 0,177 & 0,176 & 0,068 & 0,120 & 0,121 & 0,161 & $\begin{array}{lll}0,170 & 0,169\end{array}$ & 0,030 & 0,070 & 0,071 \\
\hline B. subtilis & 0,114 & 0,116 & 0,116 & 0,086 & 0,113 & 0,112 & 0,120 & $\begin{array}{lll}0,137 & 0,136\end{array}$ & 0,070 & 0,072 & 0,071 \\
\hline
\end{tabular}


a bactéria Bacillus subtilis, pois dados da literatura indicam este micro-organismo como um excelente produtor de biossurfactante. ${ }^{20}$

Os resultados obtidos da tensão superficial estão apresentados na Tabela 1.

Para a determinação do índice de emulsificação, as leituras foram realizadas após 24 h e estas permaneceram constantes por 30 dias sem que ocorresse alteração na porcentagem dos índices. Os resultados encontram-se na Tabela 2.

$\mathrm{O}$ peso celular seco da bactéria a diferentes pHs e tempos de fermentação estão apresentados na Tabela 3.

De acordo com as Tabelas 1, 2 e 3 pode-se observar que os melhores pHs foram 5,0 e 7,0 e nos tempos de fermentação de 72 $\mathrm{h}$ ocorreram as maiores porcentagens dos índices de emulsificação e, também, melhores reduções da tensão superficial. Com relação ao crescimento celular pode-se observar que este é diretamente proporcional à produção de biossurfactante, que está relacionado à diminuição da tensão superficial e índice de emulsificação.

Para o estudo das diferentes fontes de carbono em diferentes concentrações escolheu-se o $\mathrm{pH}=7,0$ devido a este ser um $\mathrm{pH}$ neutro e tempo de fermentação de $72 \mathrm{~h}$.

A glicose foi usada como fonte de carbono por vários pesquisadores..$^{9,11,18,21-23}$ Neste trabalho foram estudadas outras fontes de carbono, inclusive a sacarose e o caldo de cana, pois estas são matérias-primas abundantes no mercado nacional e de baixo custo.

As fontes de carbono testadas foram glicose, sacarose, manitol, caldo de cana, frutose e glicose + frutose nas concentrações de 1,0; 2,$0 ; 3,0 ; 4,0$ e $5,0 \%$. As análises realizadas para determinação da melhor fonte de carbono e a melhor concentração foram a determinação da tensão superficial, índice de emulsificação, atividade emulsificante (para estas análises foi utilizado o caldo de fermentação sem a presença de células) e peso celular seco. O caldo de cana foi clarificado em vapor fluente antes de seu uso.

A Figura 1 apresenta os resultados das medidas de tensão superficial em relação às fontes de carbono em diferentes concentrações, o meio base apresenta uma tensão superficial de 66,1 Din/cm (Din/cm = mN/m).

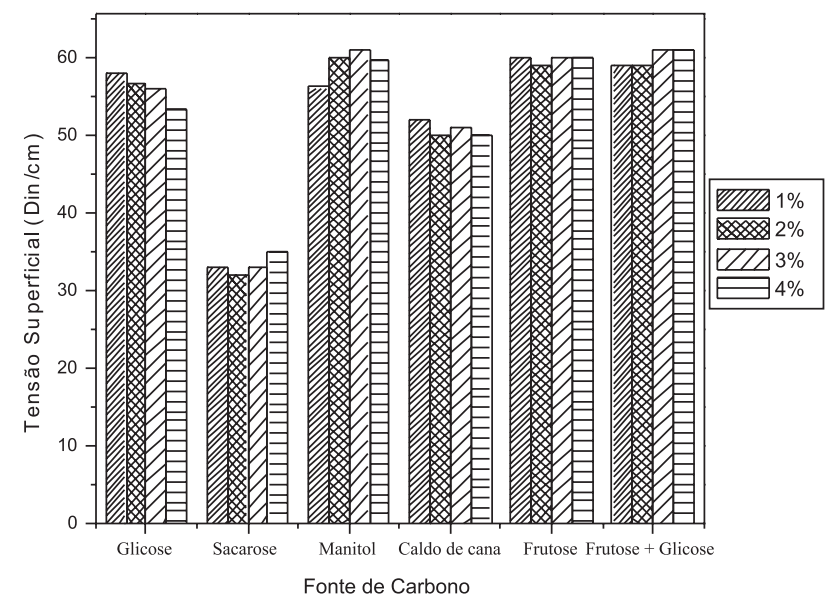

Figura 1. Determinação da tensão superficial $(\mathrm{mN} / \mathrm{m})$ no sobrenadante em diferentes concentrações das fontes de carbono

Na Figura 2 está apresentada a variação do índice de emulsificação, em coluna de tolueno, em relação às diferentes fontes de carbono em diferentes concentrações. As leituras foram realizadas após $24 \mathrm{~h}$ e permaneceram constantes por 30 dias, sem que ocorressem alterações.

O peso celular seco da bactéria Bacillus pumilus em diferentes fontes de carbono a diferentes concentrações $(1,0 ; 2,0 ; 3,0 ; 4,0$ e 5,0) está apresentado na Tabela 4 . Nesta pode-se observar novamente que o crescimento é diretamente proporcional à produção de biossurfac-

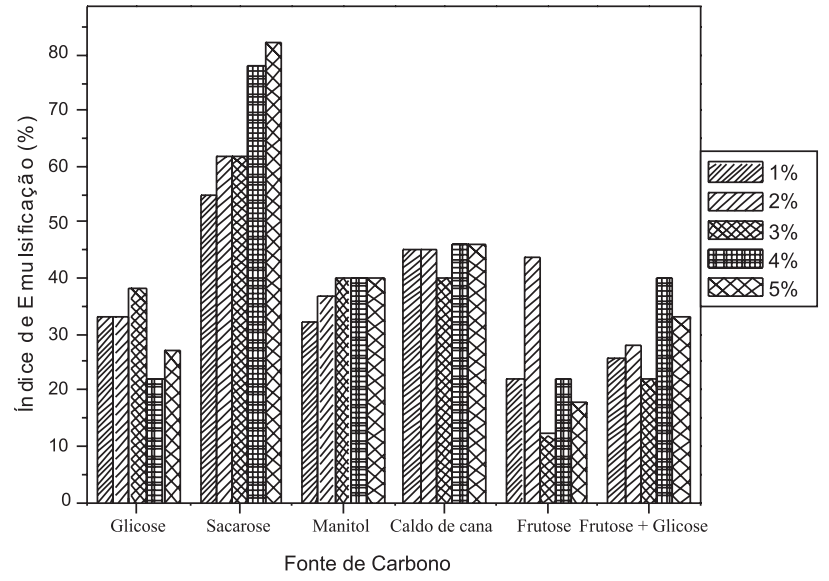

Figura 2. Porcentagem do índice de emulsificação (\%) em diferentes concentrações das fontes de carbono

tante, que está diretamente relacionado com a diminuição da tensão superficial e o aumento do índice de emulsificação.

$\mathrm{Na}$ Tabela 5 está representada a atividade emulsificante da bactéria Bacillus pumilus a $610 \mathrm{~nm}$ (o branco foi realizado da mesma maneira, com substituição do sobrenadante por água). Quanto maior a densidade óptica maior é a atividade emulsificante, o biossurfactante emulsan atinge uma densidade óptica de 2,44 a $600 \mathrm{~nm},{ }^{24}$ resultados superiores foram determinados utilizando as fontes de carbono sacarose e caldo de cana.

Através das Figuras 1 e 2 juntamente com as Tabelas 4 e 5 observou-se que a melhor fonte de carbono foi a sacarose e concentrações baixas de fontes de carbono são suficientes para estimularem alta produtividade de biossurfactante, que pode ser alcançada utilizando-se matérias-primas baratas e regionais.

Pode também ser observado que, apesar do caldo de cana ter altos teores de sacarose, a presença de outros componentes no caldo interferiu e não levou a tão alta produtividade como a sacarose pura e, também, a mistura de frutose + glicose não levou a boa produtividade, talvez pelo fato da presença de frutose inibir a produção, pois quando esta foi utilizada sozinha houve baixa produtividade do biossurfactante.

A seguir, apresenta-se a determinação da concentração micelar crítica (CMC) em meio contendo sacarose e caldo de cana nas concentrações de $2 \%, \mathrm{pH}=7,0$ e $72 \mathrm{~h}$ de fermentação a $30{ }^{\circ} \mathrm{C}$ para a bactéria Bacillus pumilus. Foram utilizados estes sobrenadantes, pois apresentaram os melhores parâmetros de produção de biossurfactante. Na Figura 3 estão apresentadas as curvas (tensão superficial vs \% do sobrenadante) para o calculo do CMC.

A concentração micelar crítica (CMC) é a concentração do surfactante que favorece a formação de micelas, uma agregação entre 50 e 100 moléculas de surfactante forma micelas. Micelas são formadas quando a parte lipofílica do surfactante não é capaz de formar pontes de hidrogênio com a solução aquosa, causando um aumento da energia livre do sistema. ${ }^{25}$

Através da Figura 3 foi determinada a CMC para a bactéria $B a$ cillus pumilus em sacarose e caldo de cana, através deste é possível observar que o CMC foi de $27 \mathrm{mg} / \mathrm{L}$ para a sacarose e $37 \mathrm{mg} / \mathrm{L}$ para o caldo de cana. Quanto mais baixa a CMC melhor é o surfactante; a surfactina produzida por Bacillus subtilis apresenta uma CMC de $23 \mathrm{mg} / \mathrm{L}$ sendo considerada um ótimo biossurfactante..$^{25,26}$

Foi realizada a produção em alta escala utilizando-se a bactéria Bacillus pumilus em sacarose a $2 \%$ em $\mathrm{pH}=7,0,72 \mathrm{~h}$ de incubação a $30{ }^{\circ} \mathrm{C}$ e $200 \mathrm{rpm}$, pois estas foram as melhores condições de produção de biossurfactante e a melhor bactéria produtora. Após a retirada das 
Tabela 4. Determinação do peso celular seco (g) em $50 \mathrm{~mL}$ do caldo de fermentação da bactéria Bacillus pumilus em diferentes concentrações das fontes de carbono

\begin{tabular}{lccccc}
\hline $\begin{array}{l}\text { Concentração } \\
(\%)\end{array}$ & 1 & 2 & 3 & 4 & 5 \\
\hline Glicose & 0,0522 & 0,0572 & 0,0672 & 0,0789 & 0,0352 \\
Sacarose & 0,1250 & 0,1508 & 0,1057 & 0,1203 & 0,1699 \\
Manitol & 0,0811 & 0,0874 & 0,0636 & 0,0800 & 0,0820 \\
Caldo de cana & 0,1203 & 0,1503 & 0,8990 & 0,1079 & 0,1499 \\
Frutose & 0,0876 & 0,0920 & 0,0891 & 0,0903 & 0,0945 \\
Frutose + & 0,1123 & 0,1203 & 0,1201 & 0,1190 & 0,1230 \\
Glicose & & & & & \\
\hline
\end{tabular}

Tabela 5. Determinação da atividade emulsificante no sobrenadante livre de células a $610 \mathrm{~nm}$ da bactéria Bacillus pumilus

\begin{tabular}{|c|c|c|c|c|c|}
\hline $\begin{array}{l}\text { Concentração } \\
(\%)\end{array}$ & 1 & 2 & 3 & 4 & 5 \\
\hline Glicose & 0,370 & 0,404 & 0,430 & 0,630 & 0,555 \\
\hline Sacarose & $0,490^{*}$ & $0,630^{*}$ & $0,600^{*}$ & $0,700^{*}$ & $0,720 *$ \\
\hline Manitol & $0,280 * *$ & $0,655^{* *}$ & $0,489 * *$ & $0,700 * *$ & $0,720 * *$ \\
\hline Caldo de cana & $0,210^{*}$ & $0,428 *$ & $0,409^{*}$ & $0,500^{*}$ & $0,540 *$ \\
\hline Frutose & 0,290 & 0,498 & 0,489 & 0,550 & 0,590 \\
\hline $\begin{array}{l}\text { Frutose + } \\
\text { Glicose }\end{array}$ & $0,310 * *$ & $0,488 * *$ & $0,400 * *$ & $0,560 * *$ & $0,540 * *$ \\
\hline
\end{tabular}

* diluição 1:10, ** diluição 1:7

células por centrifugação, o sobrenadante foi submetido à precipitação com etanol na concentração $1: 2$ a $4{ }^{\circ} \mathrm{C}$ e foi realizado o cálculo do rendimento em relação à fonte de carbono.

Para o cálculo de rendimento do biossurfactante, este foi seco em estufa a vácuo a $45^{\circ} \mathrm{C}$ e foi calculado o rendimento com relação a 1 $\mathrm{L}$ de caldo de fermentação. O resultado mostrou que a produtividade foi de $6,05 \mathrm{~g} / \mathrm{L}$, correspondendo a um rendimento de $30,25 \%$.

\section{Estudo da degradação do petróleo}

Para o estudo da degradação do petróleo, a bactéria Bacillus pumilus foi incubada em placas de Petri contendo areia (10 g), inóculo bacteriano $(2 \%)$ e petróleo $(1 \%)$ a $30{ }^{\circ} \mathrm{C}$ por 20 dias. O controle negativo não possui inóculo. Após este período estas placas foram submetidas à análise macroscópica para observação da degradação do petróleo. ${ }^{27}$ Os resultados estão mostrados na Figura 4.

Através da observação macroscópica pôde-se observar que a bactéria Bacillus pumilus degradou o petróleo bruto deixando-o o mais fluido, sendo este resultado de grande importância para o uso destas em limpeza de incrustações nas empresas de petróleo e em derramamento no meio ambiente.

\section{Determinação da atividade antimicrobiana}

Vários biossurfactantes apresentam atividade antimicrobiana como os ramnolipídeos produzidos por Pseudomonas aeruginosa, lipopeptídeos produzidos por Bacillus subtilis e glicolipídeo produzido Rhodococcus erythropolis. ${ }^{2,28}$ Neste trabalho foi realizada a atividade antimicrobiana da bactéria Bacillus pumilus.

Para a determinação da atividade antimicrobiana, foi testada a bactéria Bacillus pumilus e seus respectivos sobrenadantes (após fermentação por $72 \mathrm{~h}$, fonte de carbono sacarose a $2 \%$ e separação das células) contendo o biossurfactante; foram utilizados os sobrenadantes com $\mathrm{pH}=5$ e 7, pois estes $\mathrm{pHs}$ foram melhores para a produção de biossurfactantes.
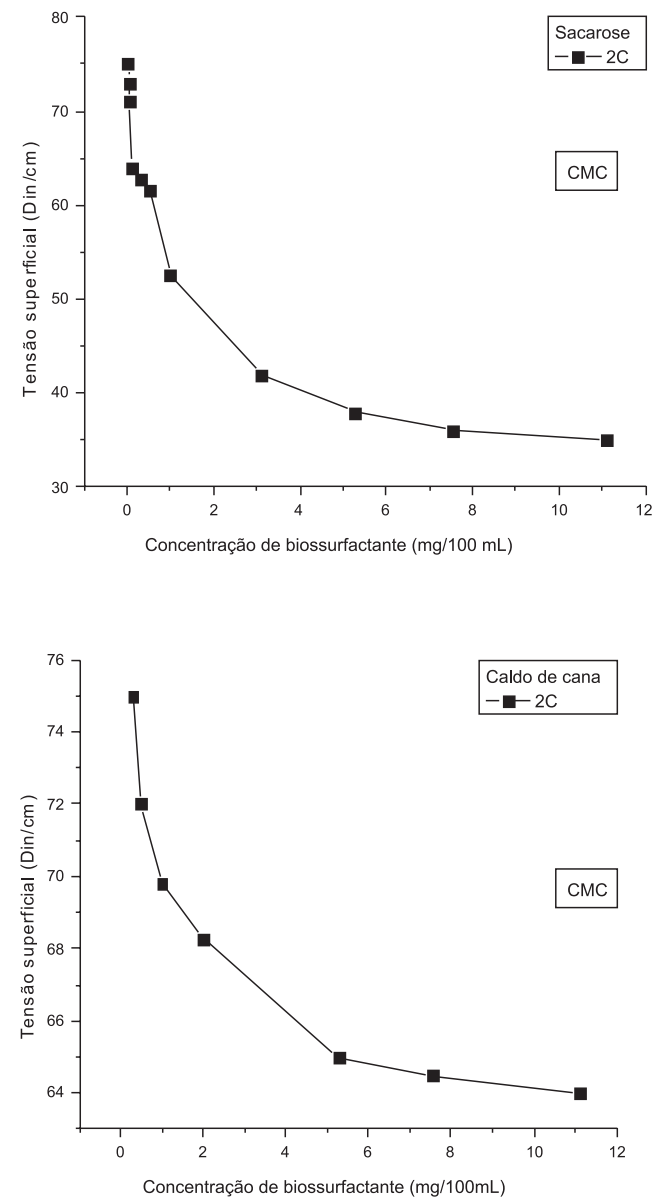

Figura 3. Determinação da concentração micelar crítica (CMC) no sobrenadante livre de células da bactéria Bacillus pumilus (2C) em: (a) sacarose $e$ (b) caldo de cana

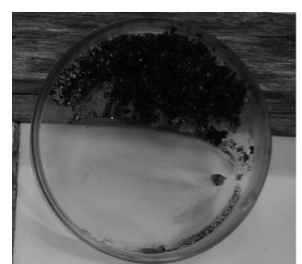

(a)

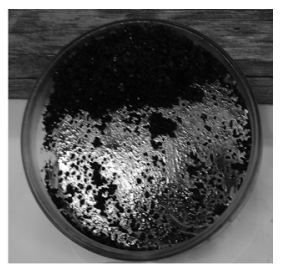

(b)
Figura 4. Análise macroscópica da fluidez do petróleo na presença do inóculo bacteriano de Bacillus pumilus

Para os testes em placas a bactéria Bacillus pumilus e seus sobrenadantes foram inoculados no meio através de impregnação em discos estéreis, os quais foram colocados nas placas de Petri contendo meio PCA, previamente inoculadas por superfície com bactérias Gram (+) Bacillus cereus, Bacillus circulans e Bacillus polymyxa e as Gram (-) Escherichia coli, Citrobacter diversus e Klebsiella pneumoniae. Os discos impregnados com a bactéria Bacillus pumilus e seus sobrenadantes também foram inoculados em placas contendo meio PDA para testar suas atividades fungicidas sobre o Aspergillus awamori. As leituras dos halos de inibição foram realizadas em 24, 48 e 72 h para as bactérias e até 5 dias para o fungo.

Para os testes em tubos de ensaio $0,1 \mathrm{~mL}$ dos sobrenadantes a $\mathrm{pH}$ 5,0 e 7,0 foram inoculados em tubos contendo caldo nutriente, previamente inoculadas com as bactérias e o fungo acima descritos. Foi realizado um acompanhamento do crescimento dos micro-organismos testados em tubos sem a presença de biossurfactante. As leituras foram 
realizadas em espectrofotômetro a $620 \mathrm{~nm}$ em 24,48 e $72 \mathrm{~h}$ para as bactérias e até 5 dias para o fungo.

A bactéria Bacillus pumilus e seus sobrenadantes, a $\mathrm{pH}$ 5,0 e 7,0, não apresentaram halos de inibição, indicando que não possuem atividade bactericida e fungicida sobre os micro-organismos testados.

Com relação aos testes em tubos de ensaio onde este é mais sensível, foi observada atividade bacteriostática e fungistática do sobrenadante a $\mathrm{pH}=7,0$ do Bacillus pumilus para todas as bactérias e o fungo testados, onde esta atividade foi observada pela diminuição das leituras de densidade óptica, quando comparada às leituras realizadas nas soluções destes micro-organismos sem a presença do biossurfactante. Os resultados estão na Tabela 6.

Tabela 6. Determinação da leitura óptica em espectrofotômetro a $620 \mathrm{~nm}$ por 24, 48 e $72 \mathrm{~h}$ para as bactérias testadas e até 5 dias para o fungo com e sem a presença de sobrenadante a $\mathrm{pH}=7,0$

\begin{tabular}{|c|c|c|c|c|}
\hline Gram (+) & $24 \mathrm{~h}$ & $48 \mathrm{~h}$ & $72 \mathrm{~h}$ & 5 dias \\
\hline Bacillus cereus & $\begin{array}{c}0,0000^{*} \\
0,0968 * *\end{array}$ & $\begin{array}{c}0,0183^{*} \\
0,1404 * *\end{array}$ & $\begin{array}{c}0,1872 * \\
0,6199 * *\end{array}$ & \\
\hline Bacillus circulans & $\begin{array}{c}0,0000^{*} \\
0,0587 * *\end{array}$ & $\begin{array}{c}0,0548^{*} \\
0,1248^{* *}\end{array}$ & $\begin{array}{c}0,0153^{*} \\
0,5904 * *\end{array}$ & \\
\hline Bacillus polymyxa & $\begin{array}{c}0,0000^{*} \\
0,2174 * *\end{array}$ & $\begin{array}{c}0,0427 * \\
0,2894 * *\end{array}$ & $\begin{array}{c}0,1830 * \\
0,8211 * *\end{array}$ & \\
\hline Gram (-) & $24 \mathrm{~h}$ & $48 \mathrm{~h}$ & $72 \mathrm{~h}$ & 5 dias \\
\hline Escherichia coli & $\begin{array}{c}0,0000 * \\
0,1172 * *\end{array}$ & $\begin{array}{c}0,0205^{*} \\
0,2022^{* *}\end{array}$ & $\begin{array}{c}0,3872 * \\
0,7342 * *\end{array}$ & \\
\hline Citrobacter diversus & $\begin{array}{c}0,0005^{*} \\
0,1331 * *\end{array}$ & $\begin{array}{c}0,0996^{*} \\
0,2337 * *\end{array}$ & $\begin{array}{c}0,1143 * \\
0,7980 * *\end{array}$ & \\
\hline Klebsiella pneumoniae & $\begin{array}{c}0,0000^{*} \\
0,1245^{* *}\end{array}$ & $\begin{array}{c}0,0125^{*} \\
0,2059^{* *}\end{array}$ & $\begin{array}{c}0,1098^{*} \\
0,6700^{* *}\end{array}$ & \\
\hline Fungo & $24 \mathrm{~h}$ & $48 \mathrm{~h}$ & $72 \mathrm{~h}$ & 5 dias \\
\hline Aspergillus awamori. & $\begin{array}{c}0,0000 * \\
0,0000 * *\end{array}$ & $\begin{array}{c}0,0253^{*} \\
0,2395^{* *} \\
\end{array}$ & $\begin{array}{c}0,2525^{*} \\
0,7201^{* *}\end{array}$ & $\begin{array}{l}0,3066 * \\
0,980 * *\end{array}$ \\
\hline
\end{tabular}

* com a presença de biossurfactante; ** sem a presença de biossurfactante

\section{Purificação e identificação do biossurfactante}

O biossurfactante foi purificado por meio de diálise e submetido à determinação de proteína pelo método de Kjeldahl, ${ }^{12}$ presença de lipídeos por Bligh-Dyer, ${ }^{13}$ açúcares redutores e açúcares totais por Somogy-Nelsone Dubois, ${ }^{14-16}$ além da análise de ressonância nuclear magnética (RMN) apresentada na Figura 5.

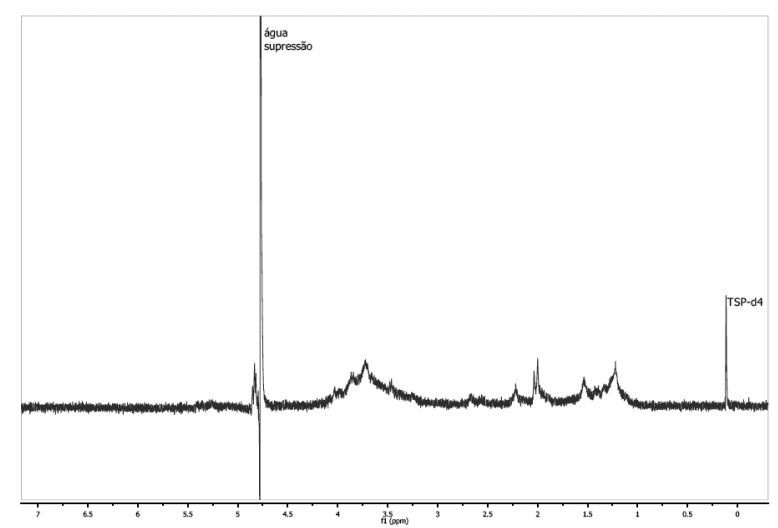

Figura 5. Espectro de ressonância magnética nuclear (RMN) do biossurfactante produzido por Bacillus pumilus

Na Figura 5 podem-se observar picos na região de 3,2-3,8 ppm indicando a presença de $\left(\mathrm{CH}_{2}-\mathrm{CH}_{2}-\mathrm{O}\right)_{n} \mathrm{e}\left(\mathrm{CH}_{2}-\mathrm{CHO}-\mathrm{CH}_{3}\right)_{n}$, picos na região de 1,2 ppm indicam a presença de $\left(\mathrm{CH}_{2}\right)_{\mathrm{n}}$ na estrutura do bios- surfactante. O pico localizado na região de 2 ppm está correlacionado com o solvente. Entre os compostos presentes estão carboidratos, lipídeos e proteínas.

Pelas análises individuais de proteínas, lipídeos e carboidratos foram constatadas presenças de $5 \%$ de proteínas, $8 \%$ de lipídeos e $80,4 \%$ de açúcares redutores totais, indicando que a molécula do biopolímero tem alto peso molecular e está formada por um complexo lipopolissacarídeo-proteína.

\section{CONCLUSÕES}

A bactéria Bacillus pumilus produtora de biossurfactantes foi isolada de solo contaminado com hidrocarbonetos e sua identificação foi realizada por meio de testes bioquímicos e análise de PCR. A melhor produção de biossurfactantes foi em pH 5,0 e 7,0 após $72 \mathrm{~h}$ de fermentação, utilizando-se como fonte de carbono sacarose em baixas concentrações, sendo esta uma matéria-prima regional e viável economicamente. A bactéria testada foi capaz de degradar o petróleo bruto, fazendo com que este ficasse mais fluido, e esta bactéria não apresentou atividade antimicrobiana, apenas atividades bacteriostática e fungistática. A partir da análise da composição centesimal do biossurfactante constatou-se a presença de uma molécula de biopolímero de alto peso molecular formada por um complexo lipopolissacarídeo-proteína.

\section{REFERÊNCIAS}

1. Mulligan, C. N.; Environ. Pollut. 2005, 133,183.

2. Banat, I. M.; Makkar, R. S.; Cameotra, S. S.; Appl. Microbiol. Biotechnol. 2000, 53, 495.

3. Fiechter, A.; Trends Biotechnol. 1992, 10, 208

4. Maier, R. M.; Soberón-Chávez, G. ;Appl. Microbiol. Biotechnol. 2000, 54,625 .

5. Makkar, R. S.; Cameotra, S. S.; Appl. Microbiol.Biotechnol. 2002, 58, 428.

6. Rufino, R. D.; Luna, J. M.; Sarubbo, L. A.; Resumo do $5^{\circ}$ Simpósio Latino Americano de Ciência de Alimentos, Campinas, Brasil, 2003.

7. Roy, D.; Kommalapati, R. R.; Mandava, S. S.; Environ. Sci. Technol. 1997, 31, 670 .

8. Cybulski, Z.; Dziurla, E.; Kaczorek, E.; Olszanowski, A.; Spill Sci. Technol. Bull. 2003, 8, 503.

9. Sarubbo, L. A.; Luna, J. M.; Campos-Takaki, G. M.; Electron. J. Biotecnol. 2006, 9, 400.

10. Krieg, R.; Bergey's Manual of Systematic Bacteriology, Ed. Baltimore: Williams Wilkins, 1984.

11. Bicca, F. C.; Fleck, L. C.; Ayub, M. A. Z.; Rev. Microbiol. 1999, 30, 231.

12. Joslyn, M. A.; Methods in food analysis (Physical, Chemical and Instrumental Methods of Analysis), Ed. Academic Pres: Nova York, Londres, 1970.

13. Bligh, E. C.; Dyer, W. J.; Can. J. Biochem. Physiol. 1959, 37, 911.

14. Nelson, N.; Biochemistry, 1944, 153, 375.

15. Somogy, M.; J. Biol. Chem. 1952, 195, 19.

16. Dubois, M.; Gilles, K. A.; Hamilton, J. K.; Anal. Chem. 1956, $28,350$.

17. Bueno, S. M.; Dissertação de Mestrado, Universidade Estadual Paulista, Brasil, 2001.

18. Fleurackers, S. J. J.; Eur. J. Lipid Sci. Technol. 2006, 108, 5.

19. Rajeshwari, K. V.; Prakash, G.; Ghosh, P.; Lett. Appl. Microbiol. 1995, $21,173$.

20. Barros, F. F. C.; Quadros, C. P.; Maróstica-Júnior, M. R.; Pastore, G. M.; Quim. Nova 2007, 30, 409.

21. Hua, Z. Z.; Chen, Y.; Du, G. C. J.; J. Microbiol. Biotechnol. 2004, 20, 25 . 
22. Rahman, K. S. M.; Rahman, T. J.; Kourkoutas, Y.; Petsas, I.; Marchant, R.; Banat, I. M.; Bioresour. Technol. 2003, 90, 159.

23. Vance-Harrop, M. H.; Gusmão, N. B.; Campos-Takaki, G. M.; Brazilian J. Microbiol. 2003, 34, 120.

24. Lang, S.; Curr. Opin. Colloid Interface Sci. 2002, 7, 12.

25. Christofi, N.; Ivshina, I. B.; J. Appl. Microbiol. 2002, 93, 915.
26. Mesquita, A. C.; Tese de Doutorado, Universidade Federal Rural do Rio de Janeiro, Brasil, 2004.

27. Gouveia, E. R.; Lima, D. P. A.; Duarte, M. S.; Lima, G. M. S.; Araujo, J. M.; Biotecnol. Ciência e Desenvolvimento 2003, 30, 39.

28. Lang, S.; Philp, J.; Antonie van Leeuwenhoek 1998, 74, 59. 